\title{
Perencanaan Kebutuhan Bahan Baku Pada Produksi Roti Varian Moka Studi kasus di CV. Roti bangkit
}

\author{
${\text { Istikmalatun Nuril } \mathbf{M}^{\mathbf{1}} \text {, Jono }}^{2}$, Iva Mindhayani ${ }^{3}$ \\ ${ }^{1,2,3}$ Fakultas Sains dan Teknologi, Jurusan Teknik Industri, Universitas Widya Mataram \\ Dalem Mangkubumen KT.III/237 Yogyakarta \\ Email: istikmalatunnuril.m@gmail.com, yonuwm@yahoo.co.id, ivamindhayani@gmail.com
}

\begin{abstract}
ABSTRAK
CV. Roti Bangkit merupakan perusahaan yang bergerak dalam industri makanan khususnya memproduksi roti yang berlokasi di Kadisono, Berbah, Kabupaten Sleman, Daerah Istimewa Yogyakarta. Selama ini kebutuhan bahan baku di perusahaan belum direncanakan dengan baik. Dampak dari hal tersebut ialah terjadinya penumpukan beberapa jumlah persediaan bahan baku di gudang dan munculnya biaya penyimpanan. Berdasarkan hal tersebut, maka diperlukan suatu perencanaan kebutuhan bahan baku yang baik dalam menangani permasalahan tersebut. Tujuan penelitian ini adalah untuk mengetahui jumlah permintaan, jumlah kebutuhan bahan dan menetukan metode yang tepat pada persediaan bahan baku. Perencanaan Kebutuhan Bahan Baku dengan menggunakan teknik lot sizing merupakan salah satu langkah dalam penentuan jumlah pemesanan kebutuhan bahan baku. Tiga teknik lot sizing yang digunakan adalah Least Unit Cost, Least Total Cost, dan Lot for Lot. Teknik lot sizing digunakan untuk membandingkan total biaya dengan tiga teknik lot sizing yang digunakan yaitu Least Unit Cost, Least Total Cost, dan Lot For Lot. Dengan menggunakan data penjualan roti moka bulan Desember 2018 - November 2019, didapatkan hasil peramalan permintaan bulan Desember 2019 sebanyak 33.280 buah roti moka. Berdasarkan tiga teknik lot sizing yang digunakan maka didapatkan kesimpulan metode Least Total Cost dipilih sebagai metode paling efisien karena menghasilkan biaya persediaan bahan baku produk roti varian moka paling sedikit dibandingkan dengan metode lot sizing yang lainnya, dengan biaya persediaan tepung terigu Rp 42.068,52; susu bubuk Rp 34.108,18; pengembang Rp 16.439,73; mentega Rp 200.787,66; gula pasir Rp 35.537,95; telur ayam Rp 34.667; dan meses coklat $\mathrm{Rp} 6.335,67$.
\end{abstract}

Kata kunci: perencanaan kebutuhan bahan baku, roti moka, lot sizing

\section{ABSTRACT}

$\mathrm{CV}$. Roti Bangkit is a company engaged in the food industry in particular producing bread located in Tegaltirto, Berbah, Sleman Regency, Special Region of Yogyakarta. So far, the need for raw materials in the company has not been well planned. The impact of this is the accumulation of some amount of raw material inventory in the warehouse and the emergence of storage costs. Based on this, we need a good raw material needs planning in dealing with these problems. The purpose of this study is to determine the amount of demand, the amount of material requirements and determine the right method for the supply of raw materials. Raw Material Requirement Planning using lot sizing technique is one of the steps in determining the amount of ordering raw material requirements. Three lot sizing techniques used are Least Unit Cost, Least Total Cost, and Lot for Lot. Lot sizing technique is used to compare the total cost with three lot sizing techniques used, namely Least Unit Cost, Least Total Cost, and Lot For Lot. Using data on sales of mocha bread in December 2018 - November 2019, the forecast results obtained from December 2019 were 33,280 mocha breads. Based on the three lot sizing techniques used, it was concluded that the Least Total Cost method was chosen as the most efficient method because it produced the lowest inventory cost of mocha bread product variants compared to the other lot sizing methods, with the cost of flour inventory Rp 42.068,52; milk powder Rp 34.108,18; developer Rp 16.439,73; butter Rp 200.787,66; granulated sugar Rp 35.537,95; chicken eggs $R p$ 34.667; and chocolate meses $R p$ 6.335,67.

Keywords: planning for raw material requirements, mocha bread, lot sizing

\section{PENDAHULUAN}

Perencanaan dan penjadwalan produksi di dalam sebuah perusahaan memungkinkan perusahaan untuk mengontrol fluktuasi permintaan yang ekstrim dan mengontrol jumlah persediaan. Perencanaan produksi yang tidak tepat dapat mengakibatkan tingginya atau rendahnya tingkat persediaan, sehingga 
mengakibatkan peningkatan ongkos simpan atau ongkos kehabisan persediaan. Dengan perencanaan produksi yang tepat maka kelebihan barang yang mengakibatkan timbulnya biaya ataupun kekurangan barang yang mengakibatkan hilangnya potensi penjualan dapat dihindarkan. Kelancaran proses produksi akan menjamin tersedianya produk untuk diantarkan kepada konsumen secara tepat waktu. Ketepatan waktu ini akan mendorong timbulnya loyalitas konsumen sehingga dapat meningkatkan daya saing perusahaan terhadap pesaingnya. Metode ini terbukti efektif jika dibandingkan dengan metode yang lain karena bisa menurunkan cost akibat yang timbul dan tidak diperlukan.

Terdapat banyak kendala-kendala yang timbul, terutama yang terkait dengan bahan baku, semua itu dapat diatasi, salah satunya dengan melakukan perencanaan produksi yang baik melalui peramalan kebutuhan setiap bahan baku serta dilakukan teknik penghitungan menggunakan teknik lot sizing, sehingga diketahui teknik yang sesuai untuk perusahaan.

\section{METODE PENELITIAN}

Berikut merupakan metode penelitian yang digunakan adalah sebagai berikut:

2.1 Lokasi Penelitian

Penelitian ini dilakukan di CV. Roti Bangkit yang beralamat di Kadisono, Tegaltirto, Kec. Berbah, Kabupaten Sleman, Daerah Istimewa Yogyakarta 55573.

2.2 Data yang Dikumpulkan

Data yang digunakan dalam penelitian adalah sebagai berikut:

1. Data permintaan penjualan roti varian moka satu tahun sebelumnya

2. Data kebutuhan bahan baku pada produk roti moka, antara lain:
a. Tepung terigu
b. Telur
c. Mentega
d. Susu bubuk
e. Pengembang
f. Gula
g. Meses Coklat

2.3 Pengumpulan Data

Teknik pengumpulan data yang dilakukan dalam proses penelitian di CV. Roti Bangkit dengan melakukan wawancara terhadap pegawai bagian gudang dan pemasaran yang terdapat di perusahaan. Berikut merupakan data yang dibutuhkan:

1. Data permintaan satu tahun yaitu bulan Desember 2018 - November 2019

2. Data kebutuhan bahan baku untuk produksi roti varian moka di CV. Roti Bangkit

3. Data biaya pengadaan bahan baku terdiri dari:
a. Biaya pesan
b. Biaya simpan
c. Harga bahan baku

2.4 Pengolahan Data

Data yang telah dikumpulkan dilakukan pengolahan data. Berikut merupakan pengolahan data yang dilakukan:

1. Menghitung peramalan bulan desember 2019 dengan menggunakan metode moving average

2. Menghitung jumlah kebutuhan bahan baku untuk bulan berikutnya berdasarkan hasil peramalan

3. Menghitung total biaya pengadaan bahan baku produk roti moka menggunakan metode lot sizing untuk mengetahui metode yang paling efisien. Berikut merupakan metode lot sizing yang digunakan:

a. Teknik Least Unit Cost, teknik ini menggunakan konsep pemesanan dengan ongkos unit terkecil, yang diperoleh dari penjumlahan antara ongkos pesan dan ongkos simpan per unit.

b. Teknik Least Total Cost, teknik ini menggunakan konsep memilih ongkos total minimum, yang diperoleh dari penggabungan ongkos simpan yang mendekati ongkos pesan.

c. Teknik Lot For Lot, teknik ini mempunyai persamaan yaitu jumlah yang dipesan sama dengan jumlah yang dibutuhkan.

Langkah-langkah diagram alir pada penelitian ini dapat dilihat pada diagram berikut ini: 


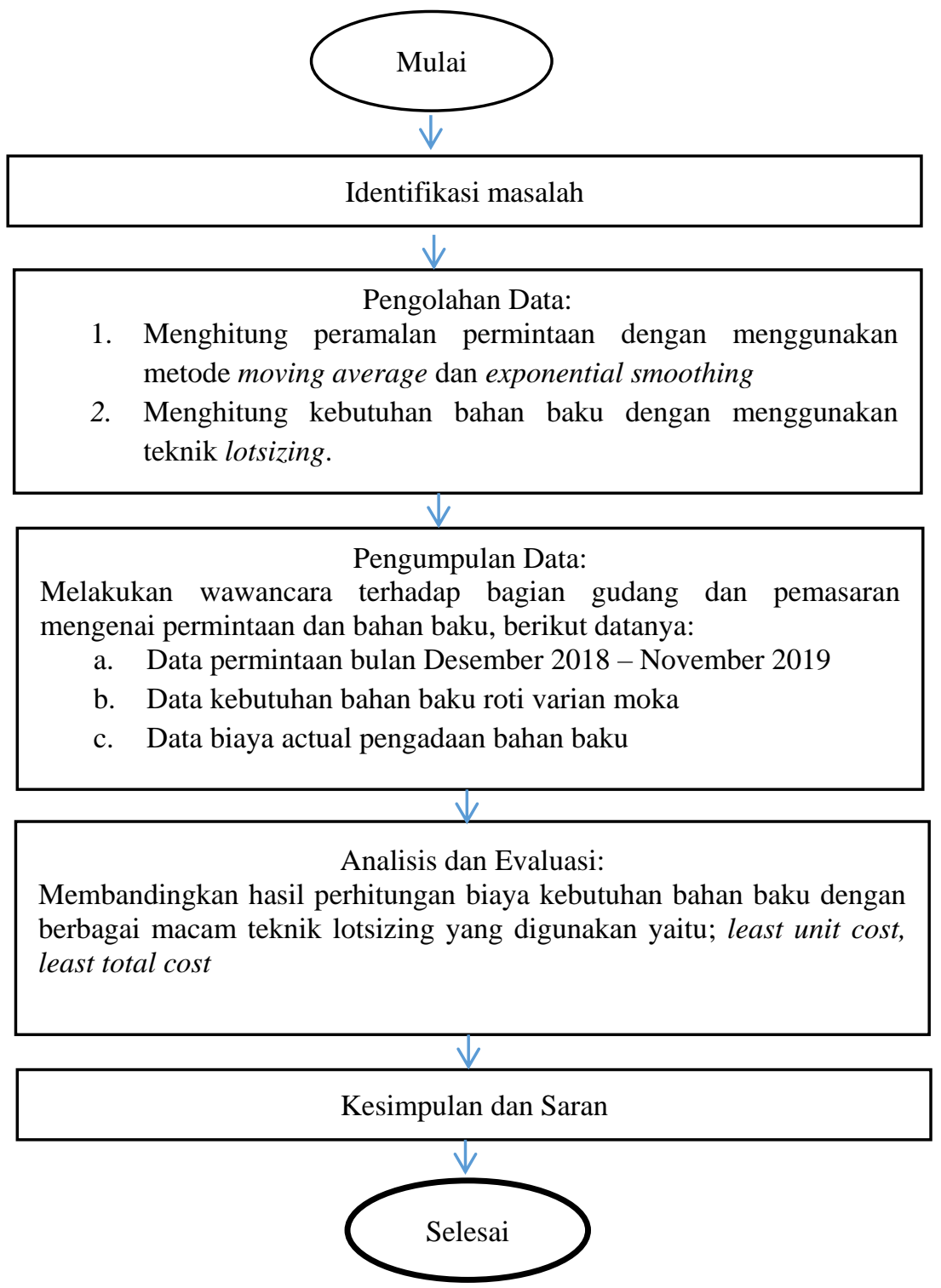

Gambar 1. Diagram Alir Penelitian

\section{HASIL DAN PEMBAHASAN}

\subsection{Data Kebutuhan Bahan Baku}

Data kebutuhan baku yang digunakan pada penelitian ini meliputi, bahan baku tepung terigu, susu bubuk, mentega, gula pasir, telur, pengembang, dan meses coklat. Data kebutuhan bahan baku untuk setiap produksi roti moka dapat dilihat pada tabel berikut:

Tabel 1. Kebutuhan Bahan Baku untuk Setiap Produksi 1 buah Roti Moka

\begin{tabular}{lc}
\hline \multicolumn{1}{c}{ Item } & Kebutuhan per $\mathbf{1}$ buah roti (gr) \\
\hline Tepung Terigu & 8,3 \\
Susu Bubuk & 0,9 \\
Pengembang & 0,1 \\
Mentega & 12,5 \\
Gula Pasir & 2,6 \\
Telur Ayam & 0,6 \\
Meses Coklat & 0,0025 \\
\hline
\end{tabular}

(Sumber: CV. Roti Bangkit) 


\subsection{Data Aktual Biaya Simpan dan Biaya Pesan di Perusahaan}

Berikut merupakan data aktual frekuensi pemesanan kebutuhan bahan baku untuk produk roti varian moka yang dilakukan oleh perusahaan CV. Roti Bangkit:

Tabel 2. Data Rincian Biaya Penyimpanan Per Item

\begin{tabular}{lr}
\hline Item & Biaya Penyimpan Per item (Rp) \\
\hline Tepung Terigu & 4.285 \\
Susu Bubuk & 4.285 \\
Pengembang & 4.285 \\
Mentega & 4.285 \\
Gula Pasir & 4.285 \\
Telur Ayam & 4.285 \\
Meses Coklat & 4.285 \\
Total & 30.000 \\
\hline (Sumber: CV. Roti Bangkit)
\end{tabular}

Tabel 3. Data Biaya Pemesanan Kebutuhan Bahan Baku

\begin{tabular}{|c|c|c|c|c|c|}
\hline Item & $\begin{array}{c}\text { Biaya } \\
\text { Telefon } \\
\text { (Rp) } \\
(1)\end{array}$ & $\begin{array}{c}\text { Biaya } \\
\text { Kirim } \\
(\mathbf{R p}) \\
(\mathbf{2})\end{array}$ & $\begin{array}{c}\text { Biaya } \\
\text { Pesan } \\
(\mathbf{R p}) \\
(3) \\
(1+2) \\
\end{array}$ & $\begin{array}{c}\text { Frekuensi } \\
\text { Pemesanan } \\
\text { tiap Bulan } \\
\text { (4) }\end{array}$ & $\begin{array}{c}\text { Tot. Biaya } \\
\text { Penga. Bahan } \\
\text { Baku (Rp) } \\
(5) \\
(3 \times 4) \\
\end{array}$ \\
\hline $\begin{array}{l}\text { Tepung } \\
\text { Terigu }\end{array}$ & 1.050 & 15.000 & 16.050 & 6 kali & 96.300 \\
\hline $\begin{array}{c}\text { Susu } \\
\text { Bubuk }\end{array}$ & 1.050 & 5.000 & 6.050 & 3 kali & 18.150 \\
\hline $\begin{array}{c}\text { Pengemban } \\
\mathrm{g}\end{array}$ & 1.050 & 15.000 & 16.050 & 4 kali & 64.200 \\
\hline Mentega & 1.050 & 15.000 & 16.050 & 4 kali & 64.200 \\
\hline Gula Pasir & 1.050 & 5.000 & 3.050 & 3 kali & 9.150 \\
\hline $\begin{array}{l}\text { Telur } \\
\text { Ayam }\end{array}$ & 1.050 & 2.000 & 3.050 & 3 kali & 9.150 \\
\hline $\begin{array}{l}\text { Meses } \\
\text { Coklat }\end{array}$ & 1.050 & 2.000 & 6.050 & 2 kali & 12.100 \\
\hline & & & & Total & 273.250 \\
\hline
\end{tabular}

Tabel 4. Data Biaya Total Kebutuhan Bahan Baku

\begin{tabular}{|c|c|c|c|}
\hline Item & $\begin{array}{c}\text { Biaya Penyimpanan } \\
\text { (Rp) } \\
(\mathbf{1})\end{array}$ & $\begin{array}{c}\text { Total Biaya } \\
\text { Pengadaan Bahan } \\
\text { Baku (Rp) } \\
(2) \\
\end{array}$ & $\begin{array}{c}\text { Tot. Biaya } \\
\text { Keseluruhan }(\mathrm{Rp}) \\
(3) \\
(1+2) \\
\end{array}$ \\
\hline $\begin{array}{l}\text { Tepung } \\
\text { Terigu }\end{array}$ & 4.285 & 96.300 & 100.585 \\
\hline Susu Bubuk & 4.285 & 18.150 & 22.435 \\
\hline Pengembang & 4.285 & 64.200 & 68.485 \\
\hline Mentega & 4.285 & 64.200 & 68.485 \\
\hline Gula Pasir & 4.285 & 9.150 & 13.435 \\
\hline Telur Ayam & 4.285 & 9.150 & 13.435 \\
\hline \multirow[t]{2}{*}{ Meses Coklat } & 4.285 & 12.100 & 16.385 \\
\hline & Total & 273.250 & 303.245 \\
\hline
\end{tabular}

(Sumber: CV. Roti Bangkit)

\subsection{Data Peramalan Permintaan Bahan Baku}

Penentuan peramalan bulan Desember 2019 sebesar 33.280 buah roti moka dilakukan dengan menggunakan metode moving average periode 2. Data yang digunakan adalah data kebutuhan bahan baku meliputi tepung terigu, susu bubuk, pengembang, mentega, gula pasir, telur, dan meses coklat. Berikut 
merupakan tabel persediaan kebutuhan bahan baku per November 2019 dan data peramalan kebutuhan bahan baku bulan Desember 2019: dengan menggunakan Rumus metode peramalan moving average yaitu: Single Moving Average. Metode single moving average merupakan metode peramalan yang dilakukan pada data masa lalu untuk satu periode yang telah memiliki pola rata - rata. Berikut merupakan rumus fungsi peramalan:

$$
\mathrm{Y}_{\mathrm{t}+1}^{\prime}=\frac{T t-n+1+\cdots \ldots .+T t+1+T t}{n}
$$

Keterangan:

$$
\begin{array}{ll}
\mathrm{Tn} & : \text { Data pada periode } \mathrm{n} \\
\mathrm{n} & : \text { Jumlah deret waku yang digunakan } \\
\mathrm{Y}^{\top} \mathrm{t}+1 & : \text { Nilai peramalan periode } \mathrm{t}+1
\end{array}
$$

Tabel 5. Data Persediaan Kebutuhan Bahan Baku Per November 2019

\begin{tabular}{lccr}
\hline \multicolumn{1}{c}{ Item } & $\begin{array}{c}\text { Persediaan } \\
(\mathbf{1})\end{array}$ & $\begin{array}{c}\text { Satuan } \\
(\mathbf{2})\end{array}$ & $\begin{array}{c}\text { Total Persediaan } \\
(\mathbf{K g}) \\
(\mathbf{3})=\mathbf{1} \mathbf{~} \mathbf{2}\end{array}$ \\
\hline Tepung Terigu & $20 \mathrm{sak}$ & $\mathrm{Sak} / 25 \mathrm{~kg}$ & $500 \mathrm{Kg}$ \\
Susu Bubuk & $2 \mathrm{sak}$ & $\mathrm{Sak} / 25 \mathrm{~kg}$ & $50 \mathrm{Kg}$ \\
Pengembang & $2 \mathrm{kardus}$ & $\mathrm{kardus} / 5 \mathrm{~kg}$ & $10 \mathrm{Kg}$ \\
Mentega & $3 \mathrm{karton}$ & Karton/ $15 \mathrm{~kg}$ & $45 \mathrm{Kg}$ \\
Gula Pasir & $4 \mathrm{sak}$ & $\mathrm{sak} / 25 \mathrm{~kg}$ & $100 \mathrm{Kg}$ \\
Telur & $1.5 \mathrm{peti}$ & Peti/ $15 \mathrm{~kg}$ & $22,5 \mathrm{Kg}$ \\
Meses Coklat & $1 \mathrm{karton}$ & Karton/ $15 \mathrm{~kg}$ & $15 \mathrm{Kg}$ \\
& & Total & $743 \mathrm{Kg}$ \\
\hline
\end{tabular}

(Sumber: Hasil Pengolahan Data, 2019)

\begin{tabular}{|c|c|c|c|c|}
\hline Item & $\begin{array}{c}\text { Keb per } 1 \\
\text { roti }(\mathrm{gr}) \\
\quad(1)\end{array}$ & $\begin{array}{c}\text { Peramalan } \\
\text { Kebutuhan } \\
\text { Bulan } \\
\text { Desember } \\
2019 \\
(2)\end{array}$ & $\begin{array}{c}\text { Kebutuhan } \\
\text { Bulan } \\
\text { Desember } 2019 \\
(\text { gr }) \\
(3)=1 \times 2\end{array}$ & $\begin{array}{c}\text { Kebutuhan } \\
\text { Bulan } \\
\text { Desember } 2019 \\
(\mathrm{Kg}) \\
(4)=3 / 1000\end{array}$ \\
\hline $\begin{array}{l}\text { Tepung } \\
\text { Terigu }\end{array}$ & 8,3 & 33.280 & 276.224 & 276 \\
\hline Susu Bubuk & 0,9 & 33.280 & 29.952 & 30 \\
\hline Pengembang & 0,1 & 33.280 & 3328 & 3 \\
\hline Mentega & 12,5 & 33.280 & 416.000 & 416 \\
\hline Gula Pasir & 2,6 & 33.280 & 86.528 & 87 \\
\hline Telur Ayam & 0,6 & 33.280 & 19.968 & 20 \\
\hline Meses & 0,0025 & 33.280 & 83,2 & 0.08 \\
\hline Coklat & & Tota & 832.083 & 832 \\
\hline
\end{tabular}

Berdasarkan Tabel 5. persediaan diperoleh dari data perusahaan persediaan perbulan November 2019. Total persediaan diperoleh dari perkalian persediaan dengan banyaknya satuan.

Tabel 6. Data Peramalan Kebutuhan Bahan Baku Bulan Desember 2019

(Sumber: Hasil Pengolahan Data, 2019)

\subsection{Biaya Pemesanan dan Biaya Penyimpanan}

1. Pemesanan lewat telepon rata-rata membutuhkan waktu 3 menit. Biaya telepon memiliki tarif sebesar Rp. 350,- per menit. Berikut merupakan tabel data biaya pemesanan: 
Tabel 7. Data Biaya Setup

\begin{tabular}{lccc}
\hline \multicolumn{1}{c}{ Item } & $\begin{array}{c}\text { Biaya Telepon } \\
(\mathbf{R p})\end{array}$ & $\begin{array}{c}\text { Biaya Pengiriman } \\
(\mathbf{R p})\end{array}$ & Biaya Setup (Rp) \\
\hline Tepung & 1.050 & 15.000 & 16.050 \\
Terigu & & & \\
Susu Bubuk & 1.050 & 5.000 & 6.050 \\
Pengembang & 1.050 & 15.000 & 16.050 \\
Mentega & 1.050 & 15.000 & 16.050 \\
Gula Pasir & 1.050 & 2.000 & 3.050 \\
Telur & 1.050 & 2.000 & 3.050 \\
Meses & 1.050 & 5.000 & 6.050 \\
Coklat & & & 66.350 \\
Total & 7460 & 5900 & \\
\hline
\end{tabular}

(Sumber: Hasil Pengolahan Data, 2019)

2. Biaya penyimpanan pada CV. Roti Bangkit hanya menitik beratkan pada biaya penerangan, dan penerangan berupa listrik di gudang di gunakan 24 jam. Biaya yang dikeluarkan perusahaan untuk penerangan gudang yang luasnya $39 \mathrm{~m}^{2}$ adalah sebesar Rp. 30.000,- per bulan. Berikut merupakan tabel data penyimpanan:

Tabel 8. Data Biaya Penyimpanan

\begin{tabular}{|c|c|c|c|}
\hline Item & $\begin{array}{c}\text { Jumlah } \\
\text { Persediaan } \\
\text { / 1bulan (Kg) } \\
\text { (1) }\end{array}$ & $\begin{array}{c}\text { Biaya Penyimpanan } \\
\text { / bulan (Rp) } \\
(2)\end{array}$ & $\begin{array}{c}\text { Biaya Penyimpanan } \\
\text { /bulan /unit (Rp) } \\
(3)=2 / 1\end{array}$ \\
\hline Tepung terigu & 500 & 4.285 & 8,57 \\
\hline Susu bubuk & 50 & 4.285 & 85,7 \\
\hline Pengembang & 400 & 4.285 & 10,71 \\
\hline Mentega & 45 & 4.285 & 95,22 \\
\hline Telur Ayam & 15 & 4.285 & 285,67 \\
\hline Gula Pasir & 100 & 4.285 & 42,85 \\
\hline Meses Coklat & 15 & 4.285 & 285,67 \\
\hline \multicolumn{2}{|c|}{ Total } & 30.000 & 814,39 \\
\hline
\end{tabular}

(Sumber: Hasil Pengolahan Data, 2019)

\subsection{Perhitungan Biaya Dengan Teknik Lot Sizing}

Perhitungan biaya dengan berbagai teknik dilakukan dengan menjumlahkan total biaya pesan dengan total biaya penyimpanan. Berikut merupakan tabel perhitungan biaya keebutuhan bahan bauku tepung terigu, susu bubuk, pengembang, mentega, gula pasir, telur ayam, dan meses coklat dengan berbagai macam teknik lot size:

Tabel 9. Data Perhitungan Biaya dengan Metode Least Unit Cost

\begin{tabular}{|c|c|c|c|c|c|c|}
\hline Item & $\begin{array}{c}\text { Biaya } \\
\text { Pesan } \\
(\mathbf{R p}) \\
(1)\end{array}$ & $\begin{array}{c}\text { Banyak } \\
\text { Pemesanan } \\
\text { (2) }\end{array}$ & $\begin{array}{c}\text { Total } \\
\text { biaya } \\
\text { pesan } \\
(\mathrm{Rp}) \\
(3)=1 \mathrm{x} \\
2 \\
\end{array}$ & $\begin{array}{c}\text { Biaya } \\
\text { Simpan } \\
(\mathbf{R p}) \\
(\mathbf{4})\end{array}$ & $\begin{array}{c}\text { Total } \\
\text { persediaan } \\
\text { (5) }\end{array}$ & $\begin{array}{c}\text { Total } \\
\text { Biaya } \\
\text { Simpan } \\
(\mathrm{Rp}) \\
(6)=4 \mathrm{x} \\
5 \\
\end{array}$ \\
\hline $\begin{array}{l}\text { Tepung } \\
\text { Terigu }\end{array}$ & 16.050 & 11 & 176.550 & 8,57 & 138 & $1.182,66$ \\
\hline Susu Bubuk & 6.050 & 11 & 66.550 & 85,7 & 15 & $1.285,5$ \\
\hline Pengembang & 16.050 & 11 & 176.550 & 10,71 & 1,67 & 17,88 \\
\hline Mentega & 16.050 & 11 & 176.550 & 95,22 & 210 & $19.996,2$ \\
\hline Gula Pasir & 3.050 & 11 & 33.550 & 42,85 & 44 & $1.885,4$ \\
\hline Telur Ayam & 3.050 & 11 & 33.550 & 285,67 & 10 & 428,5 \\
\hline \multirow[t]{2}{*}{$\begin{array}{l}\text { Meses } \\
\text { Coklat }\end{array}$} & 6.050 & 11 & 66.550 & 285,67 & 0.042 & 11,99 \\
\hline & & & & Total & 418,67 & $24.808,13$ \\
\hline
\end{tabular}

(Sumber: Hasil Pengolahan Data, 2019) 
Tabel 10. Perhitungan Biaya dengan Teknik Lot Size Metode Least Total Cost

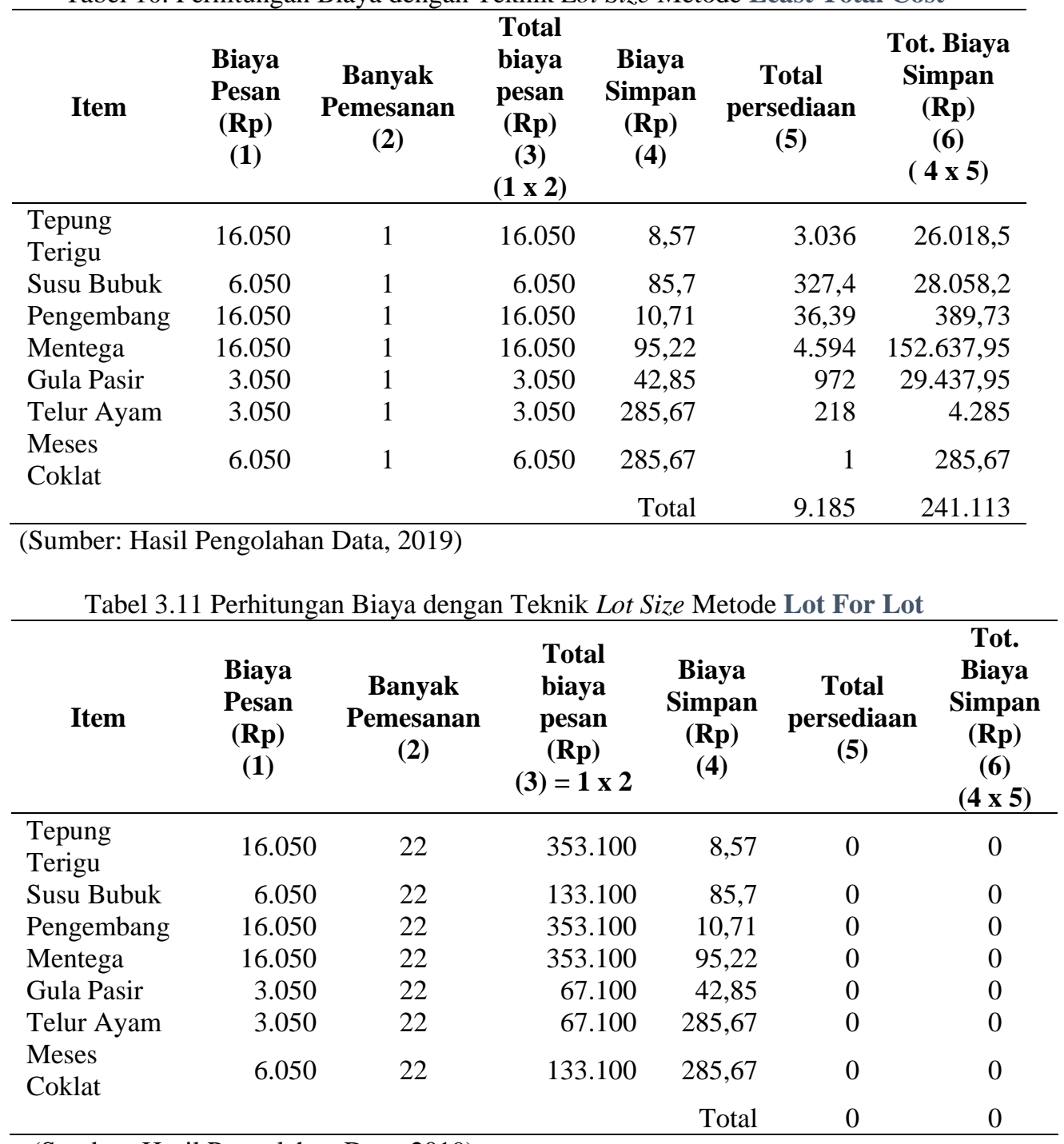

(Sumber: Hasil Pengolahan Data, 2019)

Dari tabel tampak bahwa melalui perhitungan, bahwa total biaya simpan dan total persediaan dengan ketiga metode diatas memberikan perbedaan yang sangat signifikan jika dibandingkan. Untuk total persediaan yang terbaik adalah dengan metode Least Total Cost begitu juga untuk total biaya simpan, dengan total biaya simpan RP.241.113 dan total persediannya adalah 9.185 sedangkan untuk total persediaan yang terjelek adalah dengan metode Lot For Lot begitu pula untuk total persediaan.

\section{SIMPULAN}

Berdasarkan penelitian yang telah dilakukan, maka diperoleh beberapa kesimpulan sebagai berikut:

1. Berdasarkan hasil dari peramalan permintaan untuk produk roti moka pada bulan Desember 2019 sebesar 33.280 buah roti.

2. Berdasarkan hasil dari peramalan kebutuhan setiap bahan baku untuk produk roti moka setiap bulan adalah tepung terigu $276 \mathrm{~kg}$, susu bubuk $30 \mathrm{~kg}$, pengembang $3 \mathrm{~kg}$, mentega $416 \mathrm{~kg}$, gula pasir $87 \mathrm{~kg}$, telur ayam $20 \mathrm{~kg}$, dan meses coklat $0.08 \mathrm{~kg}$.

3. Berdasarkan perhitungan dengan menggunakan metode lot sizing maka metode least total cost (LTC) dipilih karena menghasilkan biaya persediaan bahan baku produk roti moka paling efisien. 


\section{DAFTAR PUSTAKA}

Anonime. (2018). Pada Analisis\%20Perkembangan\%20Industri\%20(Edisi\%20II\%20-\%202018).pdf. Diakses pada Kamis, 17 Oktober 2019.

Assauri, Sofja. (1980). Manajemen Produksi. Jakarta. Lembaga Penerbit FE - UI.

Gasperz, Vincent. (2004). Production Planning and Inventory Control. Jakarta: PT Gramedia Pustaka Utama.

Taroreh, G.,Kawet, L., Sumarauw, J. (2016). Analisis Persediaan Bahan Baku Di Rumah Makan Sabuah Oki Sario - Manado. Jurnal Berkala Ilmiah Efisiensi, Vol. 16(06).321-330.

Handoko T. Hani. (2008). Dasar-dasar Manajemen Produksi dan Operasi. Yogyakarta (ID) : Fakultas Ekonomi Universitas Gajah Mada.

Handoko, T. Hani. (2000). Manajemen Personalia dan Sumberdaya Manusia. Edisi 2. Yogyakarta: BPFE.

Haming, Murdifin dan Mahmud Nurnajamuddin. (2014). Manajemen Produksi Mordern: Operasi Manufaktur dan Jasa. Buku Dua Edisi Kedua. Jakarta: Bumi Aksara.

Heizer J. dan B Render. (2006). Manajemen Operasi edisi 7 (Terjemahan Jilid 1). Jakarta (ID) : Salemba Empat.

Heizer, Jay, dan Barry Render. (2014). Manajemen Operasi. Edisi Kesebelas. Terjemahan oleh Kurnia Hirson, dkk. 2015. Jakarta: Salemba Empat.

Herjanto, E. (2008). Manajemen Operasi. Edisi Ketiga. Jakarta: Grasindo.

Ishak A. (2010). Manajemen Produksi. Yogyakarta (ID) : Graha Ilmu.

Khairani, Diana Sofyan. (2013). Perencanaan dan Pengendalian Produksi. Yogyakarta: Graha Ilmu.

Kumar, A. S., dan Suresh, N. (2008). Production and Operations Management: with Skill Development, Caselets, and Cases. New Delhi: New Age International (P) Limited, Publishers.

Kusuma, Hendra. (2009.) Manajemen Produksi : Perencanaan dan Pengendalian Produksi, Edisi 4. Andi: Yogyakarta.

Lundy Maulana , Retno Setyorini. (2014). Perencanaan Kebutuhan Bahan Baku Produk Windlass Dengan Menggunakan Metode Lot Sizing Pada Pt Pindad (Persero). Pada https://ejournal.upi.edu/index.php/image/article/view/2315. Diakses pada 07 Desember 2019.

Muslich. 2009. Metode Pengambilan Keputusan Kuantitatif. Bumi Aksara: Jakarta.

Nasution, Arman Hakim. (2003). Perencanaan dan Pengendalian Produksi. Surabaya: Guna Widya.

Nasution, Arman Hakim dan Yudha Prasetyawan. (2008). Perencanaan dan Pengendalian Produksi. Yogyakarta: Graha Ilmu.

Ni Ketut Dewi Ari Jayanti, Luh Putu Ayu Prapitasari. (2015.) Penerapan Metode EOQ (Economic Order Quantity) Pada Peramalan Stok Barang. Pada https://media.neliti.com/media/publications/172708-IDpenerapan-metode-eoq-economic-order-quan.pdf. Diakses pada 07 Desember 2019. 